\title{
An approach to the toxicity and toxicokinetics of aflatoxin B1 and ochratoxin A after simultaneous oral administration to fasted F344 rats
}

L.A Corcuera ${ }^{1}$, A. Vettorazzi ${ }^{1}$, L. Arbillaga ${ }^{1}$, E. González-Peñas ${ }^{2}$, A. López de Cerain ${ }^{1}$

${ }^{1}$ Department of Nutrition, Food Sciences, Physiology and Toxicology

${ }^{2}$ Department of Organic and Pharmaceutical Chemistry

Faculty of Pharmacy (C.I.F.A), University of Navarra, Irunlarrea 1, E-31008 Pamplona, Spain.

Corresponding author: Elena González-Peñas. mgpenas@,unav.es Irunlarrea 1 E-31008 Pamplona Spain. Tel.: +34.948.425652 Fax: +34.948 .425653$

E-mail addresses of all coauthors:

L.A Corcuera: 1corcuer@alumni.unav.es
A. Vettorazzi: avettora@alumni.unav.es
L. Arbillaga: larbillaga@unav.es
A. López de Cerain: acerain@unav.es 


\section{Abstract}

Humans are exposed to the hepatotoxic aflatoxin B1 (AFB1) and nephrotoxic ochratoxin A (OTA) through diet. However, kinetic and toxicological data after their co-administration are scarce.

In this study, a single oral dose of AFB1 $(0.25 \mathrm{mg} / \mathrm{kg} \mathrm{bw})+\mathrm{OTA}(0.5 \mathrm{mg} / \mathrm{kg} \mathrm{bw})$ was administered to fasted F344 rats. Blood, liver and kidney were harvested at different timepoints for mycotoxins quantification, relative weight calculation, clinical biochemistry and histopathology analysis.

Toxicity parameters pointed to acute toxicity in liver due to AFB1. No remarkable toxicity was observed in kidneys or immunological organs. Maximum observed concentrations in plasma (Cmax) were at $10 \mathrm{~min}$ and $2 \mathrm{~h}$ for AFB1 and OTA, respectively. AFB1 plasma concentration could indicate a rapid absorption/metabolism of the mycotoxin; and AFB1 liver and kidney concentrations were lower than LOQ and LOD, respectively. For OTA, Cmax was $4326.2 \mu \mathrm{g} / \mathrm{L}$ in plasma. In kidney and liver Cmax was reached at $8 \mathrm{~h}$ and concentrations were very similar between both organs at all timepoints.

Due to the low levels of AFB1, the effect of OTA on AFB1 kinetics could not be assessed. However, AFB1 seems not to affect OTA kinetics, as its profile seems very similar to kinetic studies performed only with OTA in similar conditions.

\section{Keywords}

Aflatoxin B1, ochratoxin A, toxicity, toxicokinetic, simultaneous administration 


\section{Introduction}

Mycotoxins are secondary metabolites produced by different fungal species that can be found in many agricultural commodities and processed food (Bennett and Klich, 2003). Aflatoxin B1 (AFB1) and ochratoxin A (OTA) are some of the most relevant mycotoxins due to their toxic effects and demonstrated human exposure (EFSA, 2006; EFSA, 2007).

AFB1 causes acute hepatotoxicity in humans and animals, and in severe intoxications may cause death. The International Agency for Research on Cancer (IARC) concluded that there was sufficient evidence of carcinogenicity of naturally occurring AFB1 in humans (IARC, 1993, 2002); therefore, the authorities cannot estimate a safe intake following the ALARA principle (as low as reasonably achievable) (EC, 2002). It has been described that, in humans, orally administered AFB1 follows a two-compartment model of absorption and elimination, with a rapid distribution phase followed by a slower elimination phase (EFSA, 2007). In rats, intestinal absorption of AFB1 is very fast and follows first-order kinetics (Ramos and Hernandez, 1996). Absorbed AFB1 reaches the liver through the portal system and is bioactivated by P450 cytochromes. The resulting epoxide attacks DNA forming an adduct (McLean and Dutton, 1995). AFB1 metabolism is well known (McLean and Dutton, 1995; El-Khatib et al., 1998; Smela et al., 2002; Bedard and Massey, 2006); on the contrary, data regarding kinetics of AFB1 in humans and in laboratory animals are sometimes contradictory or incomplete (IARC, 2012). In the majority of the studies carried out, the authors used methods that could not detect the AFB1 molecule or differentiate it from the resulting metabolites (Wong and Hsieh, 1980; Coulombe Jr and Sharma, 1985; Cupid et al., 2004; Jubert et al., 2009; Firmin et al., 2010).

With regard to OTA, this mycotoxin has been related with the spontaneous avian and porcine nephropathy, and with the Balkan endemic nephropathy in humans. It is a potent nephrocarcinogenic compound in rodents. However, its mechanism of genotoxicity remains controversial despite the increasing number of studies devoted to this issue. Some studies have reported formation of DNA adducts (Pfohl-Leskowicz and Castegnaro, 2005; Pfohl-Leskowicz and Manderville, 2007; Mantle et al., 2010) while others have proposed indirect genotoxic or epigenetic mechanisms (Arbillaga et al., 2004; 2007; Mally et al., 2004; 2005; Mally and Dekant, 2005; Turesky, 2005; Marin- 
Kuan et al., 2008). Some of the hypothesis regarding the mechanism of action of OTA would completely account for tumor formation, whereas others have been considered as possible contributors to it (WHO, 2008). For these reasons, the IARC classified OTA as a possible carcinogenic compound (IARC, 1993). In most animal species, the kinetic behavior of OTA has been described as a two compartment open model, although recent data regarding the accumulation in kidneys suggests that these models are too simple and should be re-analyzed using multi-compartment models (EFSA, 2006). Upon absorption from the gastrointestinal tract, OTA binds to serum proteins (approximately 99\%). This binding mostly determines its half-life in the body and considerable variations across species have been reported due to different affinity and degrees of protein binding (O'Brien and Dietrich, 2005). Reabsorption of OTA from the intestine back to the circulation can take place as a consequence of biliary recycling and may also explain some of the inter-species differences observed. Once in circulation, OTA mainly accumulates in kidney, liver and muscle (Ringot et al., 2006). In addition, reabsorption of OTA can occur in the kidney proximal and distal tubules (Ringot et al., 2006) which may also contribute to the long half-life of OTA and increased nephrotoxicity. Regarding its elimination, there are several publications supporting a different contribution of the urinary, biliar or faecal excretion routes depending on several factors such as route of administration, dose and inter-species differences in degrees of entero-hepatic circulation (Dietrich et al., 2005; Kuiper-Goodman and Scott, 1989). Vettorazzi et al. $(2009,2010,2011)$ have performed a series of kinetic studies and reported that sex, age and fasting conditions may have an impact on the kinetic profile of OTA.

Human and animal populations are exposed to multiple mycotoxins because the same food might be contaminated by more than one mycotoxin, and mycotoxins might reach humans from different sources. Co-exposure to different mycotoxins, could originate synergic or additive toxic effects on human or animal health; however, knowledge regarding this aspect or regarding the influence of co-occurrence on toxicokinetic or toxicological characteristics of the mycotoxins is still limited. There are few in vivo toxicology studies with AFB1 and OTA mixtures which gave contradictory results with respect to the endpoint studied: mortality, histopathology findings, blood parameters... In most of them the doses administered are some orders of magnitude higher than those potentially in nature and that increases the difficulty in making proper comparisons. In poultry, high doses of these mycotoxins increased mortality in a synergetic way but on 
the contrary, OTA inhibited lipid accumulation normally induced by AFB1 (Huff and Doerr, 1981; Huff et al., 1983, 1988, 1992). Other authors could not find any interaction between these mycotoxins with regard to mortality (Micco et al., 1988), relative weight of most organs, blood parameters or immunological status (Ringot et al., 2006). In swine, AFB1 and OTA had additive interactions according to liver weight and blood chemistry but they were antagonists with regard to the degree of renal cortical interstitial fibrosis and relative kidney weight (Harvey et al., 1989). On the contrary, Tapia and Seawright (1985) reported in pigs no interactions in liver and kidney toxicity at low doses, similar to real exposure. In rats, AFB1 and OTA showed no interaction regarding the measurement of mortality, weight gain, or most serum biological parameters but the anaplastic and hyperchromatic nuclei, necrosis and bile duct proliferation observed were more pronounced in the combined toxin group after 4 months (Rati et al., 1981). In rats and rabbits, the combination resulted less teratogenic than OTA alone, although some new manifestations appeared (Wangikar et al., 2004; 2005).

The main objective of this work was to study the kinetic behavior of AFB1 and OTA after a single oral dose of both mycotoxins in rats, in order to study possible changes in their pharmacokinetic profiles in relation to those reported in previous studies, due to the presence of both mycotoxins; another objective was to determine whether or not this kinetic behavior could have a role in their interaction. Moreover, toxicity parameters like clinical signs, clinical biochemistry parameters or histopathology were studied so as to obtain a more ample approach to the mixture interaction (ICH, 1994).

\section{Material and methods}

\subsection{Safety precautions}

Aflatoxin B1 and ochratoxin A are toxic substances. They were always manipulated in solution, avoiding the formation of dust and aerosols. Nitrile gloves were used for all the procedures that were carried out. During the manipulation of treated animals or contaminated samples, FPP3 masks were used.

\subsection{Chemicals and reagents}


For administration to the animals, AFB1 and OTA were purchased in powder form Sigma (Steinheim, Germany). AFB1 was dissolved in dimethyl sulfoxide (DMSO) to an initial concentration of $4.73 \mathrm{~g} / \mathrm{L}$. OTA was dissolved in $0.10 \mathrm{M} \mathrm{NaHCO}_{3}(\mathrm{pH} 7.4)$ (Riedel-deHaën, Seelze, Germany) to an initial concentration of $1.00 \mathrm{~g} / \mathrm{L}$. All the solutions were maintained at $-20^{\circ} \mathrm{C}$ until use. Aflatoxin B1 was kept in the dark to avoid degradation. The mixture of AFB1 and OTA that was administered $(0.025 \mathrm{~g} / \mathrm{L}$ and $0.050 \mathrm{~g} / \mathrm{L}$ respectively) was prepared from the initially concentrated forms.

For analytical quantification of the mycotoxins, AFB1 was purchased as a solution of 2 $\mathrm{mg} / \mathrm{L}$ in acetonitrile $(\mathrm{ACN})$ and OTA was purchased as a solution of $10 \mathrm{mg} / \mathrm{L}$ in $\mathrm{ACN}$, both from OEKANAL ${ }^{\circledR}$ Fluka (Schnelldorf, Germany) as certified reference materials. Different reference solutions were prepared mixing AFB1 and OTA in a mixture of acetonitrile: methanol 50:50 v/v. For the tissue homogenates, $\mathrm{NaH}_{2} \mathrm{PO}_{4} \cdot \mathrm{H}_{2} \mathrm{O}$ (Merck, Darmstadt, Germany) at $0.05 \mathrm{M}, \mathrm{pH} 6.50$, was used. All the reagents used for the HPLC analysis were of analytical grade. ACN and methanol (MeOH) HPLC grade and formic acid $(\mathrm{HCOOH})$ were obtained from Sigma Aldrich (St. Quentin Fallavier, France).

\subsection{Animals}

All the animals used, ten-week-old male Fisher 344 (F344) rats, were purchased from Harlan (Horst, The Netherlands). On the day of arrival, the animals were weighed (weight variation did not exceed $\pm 20 \%$ (OECD, 1984; OECD, 2009) and then distributed into polycarbonate cages with stainless steel covers for one week in order to allow acclimatization to the environmental conditions: $12 \mathrm{~h}$ day/night cycle, temperature $22 \pm 2^{\circ} \mathrm{C}$, relative humidity $55 \pm 10 \%$, standard diet (Harlan Iberica, Spain) and water ad libitum. The experiments were performed under fasting conditions, so the food was removed $12 \mathrm{~h}$ before administration. On the day of the administration, the mean weight of the animals was $187.2 \pm 5 \mathrm{~g}$. The in vivo experiments were approved by the Ethics Committee on Animal Experimentation of the University of Navarra.

\subsection{Study design and sample collection}

The animals were randomly distributed into 5 groups of 3 animals per group. After at least five days of acclimatization, the animals received oral administration of a single dose of a mixture of $0.25 \mathrm{mg} / \mathrm{kg}$ bw of AFB1 and $0.5 \mathrm{mg} / \mathrm{kg}$ bw of OTA in $\mathrm{NaHCO}_{3} \cdot \mathrm{H}_{2} \mathrm{O}(0.1 \mathrm{M} \mathrm{pH} 7.4)(0.5 \%$ DMSO). The volumes of administration were 10 
$\mathrm{mL} / \mathrm{kg}$ bw; therefore, the volume and dose administered were adjusted to the animal weight. A control group with two rats was added in order to obtain control samples and assure that no cross-contaminations occurred during the study. They received oral administration of a mixture of $\mathrm{NaHCO}_{3} . \mathrm{H}_{2} \mathrm{O}(0.1 \mathrm{M} \mathrm{pH} 7.4)$ with $0.5 \%$ DMSO.

In order to determine the AFB1 and OTA concentrations in plasma at $10 \mathrm{~min}, 30 \mathrm{~min}, 2$ $\mathrm{h}$ and $4 \mathrm{~h}$, approximately $2 \mathrm{~mL}$ of blood from 3 animals per time point were collected from the retro-orbital sinus under isoflurane anesthesia. At 8 h, 24 h, 48 h, 72 h and 96 $\mathrm{h}$, plasma was obtained by decapitation ( $\mathrm{n}=3$ per endpoint). Blood was extracted from each animal only once before sacrificing; extraction time points for each rat were chosen taking into account the time for volemia recovery (Diehl et al., 2001). After retro-orbital extraction or decapitation, blood was collected into heparinized tubes (BD Vacutainer system) for clinical biochemistry analysis and AFB1 and OTA determination. Blood samples were centrifuged $\left(1085 \times \mathrm{g}\right.$ for $15 \mathrm{~min}$ at $\left.4^{\circ} \mathrm{C}\right)$ in order to obtain plasma, which was stored at $-80^{\circ} \mathrm{C}$.

The livers and kidneys were extracted from the animals, washed with water until the external blood was removed, blotted on filter paper, and finally weighed. Kidneys were sliced longitudinally into two halves (in order to have a representative sample of all kidney parts) and the liver was cut into five pieces. One half of each kidney and a piece of the biggest lobe of each liver were fixed in $4 \%$ formaldehyde solution, dehydrated and embedded in paraffin for histopathological analysis. The other three halves of kidney and the rest of the liver pieces were packed individually (each piece), flashfrozen in liquid $\mathrm{N}_{2}$ and stored at $-80^{\circ} \mathrm{C}$ for mycotoxin determination. In order to prevent cross contamination between samples, all the dissection material was cleaned with water and rinsed with ethanol after each animal necropsy.

\subsection{Clinical biochemistry and histopathology}

In order to analyze possible weight changes in the target organs due to administration of the mycotoxins, the relative weights (RW) of liver and kidneys were calculated dividing the weight of each organ by the total weight of the animal.

Biochemical analyses of plasma samples were performed with a Hitachi 911 ${ }^{\mathrm{TM}}$ (Roche Diagnostics) analyzer using the protocols for determining standard patterns in plasma obtained from Roche: total protein $(\mathrm{g} / \mathrm{dL})$, albumin $(\mathrm{g} / \mathrm{dL})$, glucose $(\mathrm{mg} / \mathrm{dL})$, aspartate 
transaminase (AST) (U/L), alanine transaminase (ALT) (U/L), alkaline phosphatase $(\mathrm{U} / \mathrm{L})$ and urea $(\mathrm{mg} / \mathrm{dL})$.

For the histopathological examination, paraffin sections $(3 \mu \mathrm{m})$ were cut, mounted onto glass slides, and dewaxed and stained with hematoxylin and eosin (H\&E). In the observation and evaluation of each sample, the systemic anatomopathological protocol was applied, with special attention to:

- Normalcy or alteration of the architecture and proportions of the cutaneous structures.

- Presence of circulatory phenomena.

- Evaluation and quantification of degenerative or necrotic phenomena.

- Existence or absence of inflammatory phenomena, types and intensity.

- Abnormal growths: atrophy, hyperplasia, hypertrophy, neoplasia.

- Particular or special findings.

The evaluation of some of these alterations (circulatory, degeneration and/or necrosis, inflammation and growth abnormalities) was carried out by calculating the different "fields" with the adequate increases for their correct observation. Whenever necessary, measurements were taken by means of the calibrated digital system.

\subsection{Determination of mycotoxins in plasma, liver and kidney}

The concentration of mycotoxins in plasma and tissues was determined by UHPLC with fluorescence detection. The extraction procedure and the UHPLC-FLD quantification method were previously set up and validated for these biological samples (Corcuera et al., 2011). One piece of kidney or liver was homogenized in a round-bottom plastic tube with $4 \mu \mathrm{L}$ of cold sodium phosphate buffer $(0.05 \mathrm{M}, \mathrm{pH} 6.50)$ per $\mathrm{mg}$ of tissue. The tissue homogenates were aliquoted and stored for at least one day at $-80^{\circ} \mathrm{C}$ until mycotoxin extraction was carried out. The plasma samples or the tissue homogenates were kept at room temperature for $30 \mathrm{~min}$ before the extraction step. Next, $100 \mu \mathrm{L}$ of plasma or tissue homogenate were treated with $300 \mu \mathrm{L}$ of the extractive solution (ACN acidified with formic acid ( $\mathrm{HCOOH}) 1 \%$ ) which precipitated the proteins and released the mycotoxins. After mixing this in a vortex during 2 min approximately, it was 
centrifuged at $6200 \mathrm{x}$ g for $15 \mathrm{~min}$ at $4^{\circ} \mathrm{C}$ in order to separate the protein fraction from the supernatant that contained the mycotoxins. The supernatant $(200 \mu \mathrm{L})$ was evaporated under vacuum and the solid residue was resuspended in $200 \mu \mathrm{L}$ of: $\mathrm{H}_{2} \mathrm{O}(1 \%$ $\mathrm{HCOOH}): \mathrm{MeOH}: \mathrm{ACN}$ 50:50 (0,1\%HCOOH), 60:40.

Analyses were performed on a total of 63 samples (29 plasma, 17 liver and 17 kidney) in an Agilent Technologies 1200 liquid chromatographic system equipped with a fluorescence detector (G1321A model) controlled by ChemStation B.03.02 software (Hewlett-Packard). Mycotoxins were separated on an Ascentis ${ }^{\circledR}$ Express C18 column $(150 \mathrm{~mm} \times 2.1 \mathrm{~mm} ; 2.7 \mu \mathrm{m})$ from Supelco (PA, USA). The injection volume was $40 \mu \mathrm{L}$ and the flow rate was $0.9 \mathrm{~mL} / \mathrm{min}$. Chromatography was performed at $60^{\circ} \mathrm{C}$. The mobile phase was a mixture of an organic phase (A) (MeOH-ACN, 50:50, v/v) and water (B), both acidified with $0.5 \%$ of formic acid. Proportions of both organic and aqueous phases were switched between isocratic and gradient profiles during the entire analysis procedure. The elution program starts with the isocratic profile until minute 2.4 with $30 \%$ of $\mathrm{A}$, then from minute 2.4 to $2.5 \mathrm{~min}$ the organic phase increases up to $43 \%$, from minute 2.5 to $8.3 \mathrm{~min}$ another isocratic profile at $43 \%$ of $\mathrm{A}$, from minute 8.3 to 10.0 there is a last increase up to $65 \%$ of $\mathrm{A}$ and finally, from minute 10.0 the system returns to $30 \%$ of $\mathrm{A}$ to restore the starting conditions during 5 minutes. The retention times under these conditions were 2.5 minutes for AFB1 and 8.4 minutes for OTA. Before the sample entered the fluorescence detection cell, and in order to increase sensitivity for AFB1, a photoderivatization device (AURA Industries, NY, USA) with a mercury lamp $(\lambda=254 \mathrm{~nm})$ and a knitted reactor coil of $0.25 \mathrm{~mL}(5 \mathrm{~m} \mathrm{x} 0.25 \mathrm{~mm})$ was included. During the first 4 minutes of analysis, fluorescence conditions were optimized for AFB1 (excitation $366 \mathrm{~nm}$ and emission $433 \mathrm{~nm}$ wavelengths), and after that, for OTA (excitation $225 \mathrm{~nm}$ and emission $461 \mathrm{~nm}$ wavelengths).

The LOQ were $2 \mu \mathrm{g} / \mathrm{L}$ in plasma and $8 \mu \mathrm{g} / \mathrm{kg}$ in liver and kidney for both mycotoxins. The LODs for AFB1 were as follows: $0.1 \mu \mathrm{g} / \mathrm{L}$ in plasma and $0.01 \mu \mathrm{g} / \mathrm{kg}$ in kidney and liver; the LODs for OTA were: $0.3 \mu \mathrm{g} / \mathrm{L}$ in plasma and $0.01 \mu \mathrm{g} / \mathrm{kg}$ in kidney and liver. Recovery was very efficient for both mycotoxins in plasma and tissues (between 93\% and $96 \%$ for AFB1 and between $94 \%$ and $96 \%$ for OTA), and the relative standard deviation (RSD) obtained within and between day experiments was below $10 \%$ in all the matrices studied. All the mycotoxin levels obtained have been corrected by the recovery value for each matrix. 


\subsection{Statistical analysis}

Data are presented by descriptive analysis as mean \pm standard deviation (SD) of three animals. The distribution of the data was checked for normality using the Shapiro-Wilks test. The homogeneity of the variance was verified by the Levene test. The comparisons were performed using the Kruskal-Wallis test followed by the DMS test. P-values equal to or below 0.05 were accepted as the level of significance.

\section{Results}

\subsection{Clinical biochemistry and histopathology}

The treated animals did not show any clinical signs of toxicity such as weakness, anorexia or abdominal distension during the experiment. However, during the necropsies, after $48 \mathrm{~h}, 72 \mathrm{~h}$ and $96 \mathrm{~h}$, the livers of the treated animals were light red with a visible loss of color in comparison to the control animals. Moreover, in treated animals, the relative weight of the livers after $48 \mathrm{~h}, 72 \mathrm{~h}$ and $96 \mathrm{~h}$ was significantly higher than in the control animals (table 1).

The biochemical parameters of the treated animals were comparable to the control values with the exception of the transaminases: ALT and AST (table1). The increases in ALT and AST are signs of hepatocyte death due to hypoxia, fatty change or necrosis (Smith et al., 2002). Their values increased after administration of the mycotoxins, and AST reached a maximum after $48 \mathrm{~h}$, while ALT reached the maximum after $72 \mathrm{~h}$. Afterwards, the levels returned to control levels, showing a recovery of the liver after acute damage.

The most evident alterations were detected in liver while the renal alterations are the least significant. The lymphoid organs represented by the spleen, thymus and Peyer's patches showed no differences between the control and treated groups at the different observation times.

In the liver, a progressive lesional state was observed. It is characterized as follows: at 8 $\mathrm{h}$ diffuse hepatocyte necrosis, accompanied by focal hepatitis, stands out. At $24 \mathrm{~h}$ hepatocyte necrosis continues to be observed in porta spaces and parenchyma (figure. 1 B). At the same time, discreet degeneration begins to be observed in the cytoplasm of the hepatocytes and a few of these appear to be binucleated or with large nuclei. At $48 \mathrm{~h}$ 
a large number of hepatocytes present intense tumefaction and degeneration in the cytoplasms (figure. $1 \mathrm{C}$ ), while others show necrosis surrounded by inflammatory infiltrates. In the porta spaces, they proliferate with bile canaliculi and a process of fibrosis begins (figure. $1 \mathrm{C}$ ). At $72 \mathrm{~h}$, diffuse hepatocyte necrosis and the inflammatory response in the parenchyma are maintained. Degeneration of the hepatocytes in the cytoplasm is scarcely evident. Fibrosis and proliferation of bile canaliculi in the porta spaces as well as focal fibrosis of the parenchyma are notable (figure. $1 \mathrm{D}$ ). This fibrosis is interpreted as small areas of cicatrization due to the loss of hepatocytes. Together, these findings can be defined as the very initial stages of cirrhosis. At $96 \mathrm{~h}$ hepatocyte necrosis is no longer observed and the inflammatory response is either stabilized or has decreased. The cytoplasm of the hepatocytes presents tumefaction and moderate degeneration. Proliferation of bile canaliculi and portal fibrosis are largely present (figure. $1 \mathrm{E}$ ) as well as regenerative phenomena in the hepatocytes with numerous binucleated cells (figure. $1 \mathrm{~F}$ ).

In the kidney, the proximal convoluted tubules progressively lost the renal glucogen. At the same time, in the glomerules, hypercellularity was observed due to the infiltration of inflammatory cells, resulting in glomerulonephritis. Over time, sclerosis and moderate glomerular atrophy were observed. The alterations in the renal tubules were not evident and even though there was an increase of interstitial nephritis and interstitial fibrosis observed as of $48 \mathrm{~h}$, no previous serious tubular lesion was found.

\subsection{Plasma and tissue mycotoxin concentrations}

After administration of mycotoxins, OTA was found in plasma and tissues at all the timepoints, and very low levels of OTA were detected in control samples $(<\mathrm{LOQ})$, presumably due to OTA contamination of standard animal diet (Vettorazzi et al., 2009; Zepnik et al., 2003; Mantle, 2008). The amount in plasma increased as of 10 minutes and reached a maxima at $2 \mathrm{~h}\left(\mathrm{C}_{\max } \mathrm{obs}=4326.6 \mu \mathrm{g} / \mathrm{L}\right)$ (figure $\left.2 \mathrm{~A}\right)$. In tissues, the OTA concentration was similar in liver and kidney, reaching maximum levels at $8 \mathrm{~h}$ (figure 2B).

AFB1 could only be quantified in plasma at 10 and 30 minutes $(24.8$ and $9.5 \mu \mathrm{g} / \mathrm{L}$, respectively). In liver, levels below the LOQ were observed $8 \mathrm{~h}$ after administration, and no AFB1 was detected in kidney. In plasma, chromatograms showed a wide front peak, very different from the control or AFB1-spiked plasma samples. This indicated 
the presence of new compounds with more hydrophilic properties than AFB1 or OTA. In order to enlarge the front peak, chromatographic conditions were modulated and at least 8 different peaks appeared (figure 3). They had maxima at $10 \mathrm{~min}$ and then decreased in a time-dependent manner until $24 \mathrm{~h}$. After $48 \mathrm{~h}$, no peaks appeared in the front.

\section{Discussion}

The ICH guideline S3A highlights the need to integrate pharmacokinetics into toxicity testing, which should aid in the interpretation of the toxicology findings (ICH, 1994). With this aim, our study attempted to learn more about the toxic and kinetic behavior of mycotoxins AFB1 and OTA when they are administered together. Wong and Hsieh, (1980) described that rats are one of the most sensitive species to AFB1 acute toxicity and carcinogenic effects. OTA has been described as a potent nephrocarcinogen in male rodents and its kinetic profile could be influenced by sex, age and fasting conditions (Vettorazzi et al., 2010; 2011). Due to the aforementioned, young male rats were selected for this experiment. To avoid the interaction of food, the mycotoxins were administered in fasting conditions. In rats, doses from 0.2 to $12.5 \mathrm{mg} / \mathrm{kg}$ bw were used in single or repeated oral dose toxicity studies of AFB1 toxicity (Wong and Hsieh, 1980; Coulombe Jr and Sharma, 1985; Rati et al., 1981; Bannasch et al., 1985; Raj et al., 1998; Ellinger-Ziegelbauer et al., 2006; Theumer et al., 2010). A low dose of AFB1 $(0.25 \mathrm{mg} / \mathrm{kg} \mathrm{bw})$ which corresponds to approximately $3 \%$ of $\mathrm{LD}_{50}$ (Wong and Hsieh, 1980) (EFSA, 2007) was administered in order to avoid strong acute toxicity of AFB1. The single OTA dose selected $(0.5 \mathrm{mg} / \mathrm{kg}$ bw) was slightly higher than carcinogenic doses (NTP, 1989; Castegnaro et al, 1998; Mantle et al 2005). It corresponds to $2.5 \%$ of the $\mathrm{LD}_{50}(\mathrm{NTP}, 1989)$, has been used in recent studies (Zepnik et al., 2003), and was the same as that used by Vettorazzi et al. 2009; therefore, some comparisons could be made.

Although there were no signs of general toxicity during the experiment, the biochemical and histopathological results pointed to acute toxicity in liver and no remarkable toxicity in kidney or other organs. The signs of hepatotoxicity appeared $48 \mathrm{~h}$ after administration, with paleness of livers, increases in transaminases, cell necrosis and inflammatory infiltration. In concordance, the relative liver weight showed significant increases due to inflammation processes. However, the liver started a repairing process 
after $72 \mathrm{~h}$ and its effects were evident after $96 \mathrm{~h}$ because AST and ALT almost returned to normal values. At that time, the regenerative phenomena were evident by the numerous binucleated cells present. These findings coincide with the observations made by Rati et al.1981 regarding acute toxicity of AFB1, and it appears that the AFB1 and/or its toxic metabolites are eliminated (metabolized and excreted) in a range of 48 h-96 h. No remarkable toxicity was observed in kidneys or immunological organs (spleen, thymus and Peyer's patches) so OTA did not cause acute toxicity at this dose,. Therefore, we can assume that the acute toxic effects observed after the combined treatment of AFB1 and OTA were mostly due to AFB1 effect.

Very low levels of AFB1 were found in plasma after 10 or $30 \mathrm{~min}(1 \%$ and $0.4 \%$ of the administered dose, respectively). The liver AFB1 levels were lower than the LOQ (8 $\mu \mathrm{g} / \mathrm{kg}$ ) at all time points and AFB1 was undetectable in kidney. For this reason, it was not possible to calculate any kinetic parameter. These findings suggest that the absorption of AFB1 was very fast, and that the molecule was rapidly metabolized in the liver. Moreover, almost none of the unmetabolized AFB1 was distributed outside the liver, into the plasma and onto the kidneys. The compounds detected in the front peak are assumed to be AFB1 metabolites because they have not been detected in the spiked plasma sample with AFB1 and OTA nor in recent OTA kinetic studies (Vettorazzi et al., 2009; 2010; 2011). These compounds had a maxima at $10 \mathrm{~min}$, decreased in a timedependent manner until $24 \mathrm{~h}$, after which they were undetectable. Coulombe and Sharma (1985) described a two-compartmental model for AFB1 kinetics in SpragueDawley rats, reaching the maximum concentration after $3 \mathrm{~h}$ and with the plasma halflife being $91.8 \mathrm{~h}$. A more recent study found the maximum concentration $4 \mathrm{~h}$ after administration, with plasma half-life of 53 h (Firmin et al., 2010). These data describe long plasma half-lives, with long elimination phases after quantifying only AFB1 or mixed with its metabolites. These observations do not coincide with our findings in which AFB1 disappeared from plasma in 30 minutes, and its metabolites in $24 \mathrm{~h}$, and this suggested an extremely fast uptake and metabolism of AFB1. Jubert et al. 2009, observed a rapid uptake $(\mathrm{T} \max =1 \mathrm{~h})$ in humans, with urinary elimination of $95 \%$ of the dose in $24 \mathrm{~h}$, which is closer to our findings; in their work, they could not differentiate among AFB1 and its metabolites. It might be possible that OTA modifies/accelerates AFB1 metabolism in liver into very hydrophilic compounds that are rapidly excreted $(24 \mathrm{~h})$ through the kidney, but there are no studies available about 
AFB1 molecule kinetics without taking into account its metabolites, so it was hard to make proper comparisons.

With regard to OTA, the concentration profiles in plasma, liver and kidney and some of the kinetic parameters are comparable to the ones that Vettorazzi et al. $(2010,2011)$ obtained under similar conditions (figure 2A) but with OTA alone. The maximum concentration in plasma was obtained after $2 \mathrm{~h}$ and corresponded to $87 \%$ of the initial dose, which was similar to the $83 \%$ that Vettorazzi et al.2010 had reported. Moreover, as in Vettorazzi et al. (2011), the same parallelism between plasma and tissue concentrations was observed. No significant differences were observed in the OTA tissue concentrationss after $24 \mathrm{~h}$ between previous kinetic studies performed with OTA alone and the current results of OTA and AFB1 co-administration. Comparing the obtained OTA profile with other experiments and models of OTA kinetics, the differences seem to be more closely related to the age of the rats than to the presence of AFB1 in the system (Vettorazzi et al., 2009; 2010; 2011).

\section{Conclusions}

In conclusion, more specific information has been obtained regarding the behavior of the mycotoxins AFB1 and OTA in F344 rats after one oral administration. Toxicity has been observed in liver, while no remarkable toxic effects were observed in kidney. The acute toxic effects observed in liver, which were attributed to AFB1, together with the fact that AFB1 and its metabolites disappeared from plasma in $24 \mathrm{~h}$, suggest a rapid absorption and metabolization of the mycotoxin. The low AFB1 plasma levels prevented to have kinetic data and therefore to assess the influence of OTA on AFB1 kinetics.

With regard to OTA, it appeared that its plasma and tissues levels were not affected by the presence of AFB1 as the kinetic profile seemed very similar to studies performed only with OTA in similar conditions. So further investigations to confirm this hypothesis would be of great interest.

\section{Acknowledgments}


The author wishes to express her gratitude to Ms. Celia Goñi and Ms. Cecilia Gutierrez for their kind help and support during the experiments. The authors are grateful to Ms. Laura Stokes for reviewing the English version of this manuscript. L-A.C. wishes to express her gratitude to the University of Navarra-Fundación Caja Navarra and to the "Asociación de Amigos" of the University of Navarra for the grants received. The authors are grateful to the reviewers, whose comments and suggestions have helped to improve this article.

\section{Funding}

This work was supported by the Science and Innovation Ministry of Spain [AGL200801437/ALI and AGL2006-12210-C03-02/ALI] 


\section{References}

Arbillaga, L., Azqueta, A., Ezpeleta, O. and Lopez de Cerain, A., 2007. Oxidative DNA damage induced by Ochratoxin A in the HK-2 human kidney cell line: evidence of the relationship with cytotoxicity. Mutagenesis 22, 35-42

Arbillaga, L., Ezpeleta, O. and Lopez de Cerain, A., 2004. ¿Es la Ocratoxina A una micotoxina mutagénica? (Is the Ochratoxin A a mutagenic mycotoxine?). Revista de Toxicología 21, 1-10.

Bannasch, P., Benner, U., Enzmann, H. and Hacker, H.J., 1985. Tigroid cell foci and neoplastic nodules in the liver of rats treated with a single dose of aflatoxin B1. Carcinogenesis 6, 1641-1648.

Bedard, L.L. and Massey, T.E., 2006. Aflatoxin B1-induced DNA damage and its repair. Cancer Lett 241, 174-183.

Bennett, J.W. and Klich, M., 2003. Mycotoxins. Clin Microbiol Rev. 16, 497-516.

Castegnaro, M., Mohr, U., Pfohl-Leszkowicz, A; Steve, J., Steinmann, J., Tillmann, T., Michelon, J and Bartsch, H. 1998. Sex- and strainspecific induction of renal tumor by ochratoxin A in rats correlates with DNA adduction. Int. J. Cancer 77, 70-75.

Corcuera, L.A., Ibáñez-Vea, M., Vettorazzi, A., González-Peñas, E. López de Cerain, A., 2011. Validation of a UHPLC-FLD analytical method for the simultaneous quantification of aflatoxin B1 and ochratoxin a in rat plasma, liver and kidney. $\mathrm{J}$ Chromatogr B 879, 2733-2740.

Coulombe Jr, R.A. and Sharma, R.P., 1985. Clearance and excretion of intratracheally and orally administered aflatoxin B1 in the rat. Food Chem Toxicol 23, 827-830.

Cupid, B.C., Lightfoot, T.J., Russell, D., Gant, S.J., Turner, P.C., Dingley, K.H., Curtis, K.D., Leveson, S.H., Turteltaub3, K.W. and Garner, R.C., 2004. The formation of AFB1-macromolecular adducts in rats and humans at dietary levels of exposure. Food Chem Toxicol 42, 559-569.

Diehl, K.H., Hull, R., Morton, D., Pfister, R., Rabemampianina, Y., Smith, D., Vidal, J.M. and van de Vorstenbosch, C., 2001. A good practice guide to the administration of 
substances and removal of blood, including routes and volumes. J Appl Toxicol 21, 1523.

Dietrich, D.R., Heussner, A.H. and O'Brien, E., 2005. Ochratoxin A: comparative pharmacokinetics and toxicological implications (experimental and domestic animals and humans). Food. Addit. Contam 22 Suppl 1, 45-52.

EFSA, 2007. Opinion of the Scientific Panel on Contaminats in the Food Chain on a request from the Commission related to the potential increase of consumer health risk by a possible increase of the existing maximun levels for Aflatoxins in almonds, hazelnuts and pistachios and derived products. EFSA J 446, 1-127.

EFSA, 2006. Opinion of the Scientific Panel on Contaminats in the Food Chain on a request from the commision related to Ochratoxin A in food. EFSA J 365, 1-56.

El-Khatib, H.N., Akeila, M.A. and Abou El-magd, M.K., 1998. The mutagenic activity of aflatoxin B1 in rat bone marrow. Toxicol Lett 95, 176-176.

Ellinger-Ziegelbauer, H., Ahr, H.-., Gmuender, H., Pallez, C. and Koenig, J., 2006. Characteristic expression profiles induced by carcinogens in rat liver. Toxicol Lett 164, S293-S294.

EC, 2002. Commission Regulation (EC) No 472/2002 of 12 March 2002 amending Regulation (EC) No 466/2001 setting maximum levels for certain contaminants in foodstuffs (Text with EEA relevance). L 75/18.

Firmin, S., Gandia, P., Morgavi, D.P., Houin, G., Jouany, J.P., Bertin, G. and Boudra, H., 2010. Modification of aflatoxin B1 and ochratoxin A toxicokinetics in rats administered a yeast cell wall preparation. Food Addit Contam 27, 1153-1160.

Harvey, R.B., Huff, W.E., Kubena, L.F. and Phillips, T.D., 1989. Evaluation of diets contaminated with aflatoxin and ochratoxin fed to growing pigs. Am J Vet Res 50, 1400-1405.

Huff, W.E., Kubena, L.F., Harvey, R.B. and Phillips, T.D., 1992. Efficacy of hydrated sodium calcium aluminosilicate to reduce the individual and combined toxicity of aflatoxin and ochratoxin A. Poult Sci 71, 64-69. 
Huff, W.E., Kubena, L.F., Harvey, R.B. and Doerr, J.A., 1988. Mycotoxin interactions in poultry and swine. J Anim Sci 66, 2351-2355.

Huff, W.E., Doerr, J.A., Wabeck, C.J., Chaloupka, G.W., May, J.D. and Merkley, J.W., 1983. Individual and combined effects of aflatoxin and ochratoxin A on bruising in broiler chickens. Poult Sci 62, 1764-1771.

Huff, W.E. and Doerr, J.A., 1981. Synergism between aflatoxin and ochratoxin A in broiler chickens. Poult Sci 60, 550-555.

IARC, 2012. IARC Monographs on the Evaluation of Carcinogenic Risks to Humans A Review of Human Carcinogens: Chemical Agents and Related Occupations. 100F.

IARC, 2002. IARC Monographs on the Evaluation of Carcinogenic Risks to Humans. Some Traditional Herbal Medicines, Some Mycotoxins, Naphthalene and Styrene. 82, 590.

IARC, 1993. IARC Monographs on the Evaluation of Carcinogenic Risks to Humans. Some Naturally Occurring Substances: Food Items and Constituents, Heterocyclic Aromatic Amines and Mycotoxins. 56, 33.

ICH, 1994. Note for guidance of toxicokinetics: The assessment of systemic exposure in toxicity studies S3A. International Conference on Harmonisation of Technical Requirements for Registration of Pharmaceuticals for Human Use.

Jubert C., Mata J., Bench, G., Dashwood, R., Pereira, C., Tracewell, W., Turteltaub, K., Williams, D. and Bailey, G., 2009. Effects of chlorophyll and chlorophyllin on lowdose aflatoxin B (1) pharmacokinetics in human volunteers. Cancer Prev Res 2 (12), 1015-1022.

Kuiper-Goodman, T. and Scott, P.M., 1989. Risk assessment of the mycotoxin ochratoxin A. Biomed. Environ. Sci. 2, 179-248.

Mally, A. and Dekant, W., 2005. DNA adduct formation by ochratoxin A: review of the available evidence. Food Addit Contam 22 Suppl 1, 65-74.

Mally, A., Pepe, G., Ravoori, S., Fiore, M., Gupta, R.C., Dekant, W. and Mosesso, P., 2005. Ochratoxin a causes DNA damage and cytogenetic effects but no DNA adducts in rats. Chem Res Toxicol 18, 1253-1261. 
Mally, A., Zepnik, H., Wanek, P., Eder, E., Dingley, K., Ihmels, H., Volkel, W. and Dekant, W., 2004. Ochratoxin A: lack of formation of covalent DNA adducts. Chem Res Toxicol 17, 234-242.

Mantle, P.G., Faucet-Marquis V., Manderville, R.A., Squillaci, B., Pfohl-Leszkowicz, A., 2010. Structures of covalent adducts between DNA and ochratoxin a: a new factor in debate about genotoxicity and human risk assessment. Chem Res Toxicol. 23, 89-98.

Mantle, P.G., 2008. Interpretation of the pharmacokinetics of ochratoxin A in blood plasma of rats, during and after acute or chronic ingestion. Food Chem Toxicol 46, 1808-1816.

Mantle,P, G., Kulinskaya, E.and Nestler, S. 2005. Renal tumourigenesis in male rats in response to chronic dietary ochratoxin A. Food Addit. Contam. 22 suppl. 1, 58-64.

Marin-Kuan, M., Cavin, C., Delatour, T. and Schilter, B., 2008. Ochratoxin A carcinogenicity involves a complex network of epigenetic mechanisms. Toxicon 52, 195-202.

McLean, M. and Dutton, M.F., 1995. Cellular interactions and metabolism of aflatoxin: An update. Pharmac Ther 65, 163-192.

Micco, C., Miraglia, M., Benelli, L., Onori, R., Ioppolo, A. and Mantovani, A., 1988. Long term administration of low doses of mycotoxins in poultry. 2. Residues of ochratoxin A and aflatoxins in broilers and laying hens after combined administration of ochratoxin A and aflatoxin B1. Food Addit Contam 5, 309-314.

NTP, 1989. Toxicology and carcinogenesis studies of ochratoxin A (CAS No 303-47-9) in F344/N rats (gavage studies). Natl Toxicol Program Tech Rep Ser 358, 1-142.

O'Brien, E. and Dietrich, D.R., 2005. Ochratoxin A: The Continuing Enigma. Crit Rev Toxicol 35, 33-60.

OECD, 2009. OECD Guidelines for the Testing of Chemicals. Draft proposal for a revised TG417: Toxicokinetics.

OECD, 1984. OECD Guidelines for the Testing of Chemicals, Number 417: Toxicokinetics. 
Pfohl-Leszkowicz, A. and Manderville, R.A., 2007. Ochratoxin A: An overview on toxicity and carcinogenicity in animals and humans. Mol. Nutr. Food Res. 51, 61-99.

Pfohl-Leszkowicz, A. and Castegnaro, M., 2005. Further arguments in favour of direct covalent binding of ochratoxin A (OTA) after metabolic biotransformation. Food Addit. Contam. 22 Suppl 1, 75-87.

Raj, H.G., Gupta, K., Rohil, V., Bose, M., Biswas, G., Singh, S.K., Jain, S.C., Parmar, V.S., Olsen, C.E. and Wengel, J., 1998. Aflatoxin B1-induced micronuclei and cell cycle alterations in lung and bone marrow cells and their modulation by Piper argyrophyllum extract. Teratog Carcinog Mutagen 18, 249-261.

Ramos, A.J. and Hernandez, E., 1996. In situ absorption of aflatoxins in rat small intestine. Mycopathologia 134, 27-30.

Rati, E.R., Basappa, S.C., Sreenivasa Murthy, V., Ramesh, H.P., Ramesh, B.S. and Singh, G.B., 1981. The sinergistic effect of aflatoxin B1 and ochratoxin A in rats. J. Food Scie Tech 18, 176-179.

Ringot, D., Chango, A., Schneider, Y.J. and Larondelle, Y., 2006. Toxicokinetics and toxicodynamics of ochratoxin A, an update. Chem. Biol. Interact. 159, 18-46.

Smela, M.E., Hamm, M.L., Henderson, P.T., Harris, C.M., Harris, T.M. and Essigmann, J.M., 2002. The aflatoxin B(1) formamidopyrimidine adduct plays a major role in causing the types of mutations observed in human hepatocellular carcinoma. Proc Natl Acad Sci USA. 99, 6655-6660.

Smith, G.S., Hall, R.L. and Walker, R.M., 2002. 6 - Applied Clinical Pathology in Preclinical Toxicology Testing, in: Wanda M. Haschek A2Colin G. Rousseaux and Matthew A. WalligA2 Wanda M. Haschek, Colin G.Rousseaux, Matthew A. Wallig (Eds). Academic Press, San Diego, pp. 123-156.

Tapia, M.O. and Seawright, A.A.,1985. Experimental combined aflatoxin B1 and ochratoxin A intoxication in pigs. Aust Vet J. 62, 33-37.

Theumer, M.G., Cánepa, M.C., López, A.G., Mary, V.S., Dambolena, J.S. and Rubinstein, H.R., 2010. Subchronic mycotoxicoses in Wistar rats: Assessment of the in 
vivo and in vitro genotoxicity induced by fumonisins and aflatoxin B1, and oxidative stress biomarkers status. Toxicology 268, 104-110.

Turesky, R.J., 2005. Perspective: ochratoxin A is not a genotoxic carcinogen. Chem Res Toxicol 18, 1082-1090.

Vettorazzi, A., de Trocóniz, I.F., González-Peñas, E., Arbillaga, L., Corcuera, L., Gil, A.G. and López de Cerain, A., 2011. Kidney and liver distribution of ochratoxin A in male and female F344 rats. Food Chem Toxicol 49, 1935-1942.

Vettorazzi, A., Trocóniz, I.F., Gonzalez-Peñas, E., Corcuera, L.A., Arbillaga, L., Gil, A.G., Nagy, J.M., Mantle, P.G. and López de Cerain, A., 2010. Effects of fasting and gender on ochratoxin A toxicokinetics in F344 rats. Food and Chemical Toxicology 48, 3159-3166.

Vettorazzi, A., Gonzalez-Peñas, E., Troconiz, I.F., Arbillaga, L., Corcuera, L.A., Gil, A.G. and López de Cerain, A., 2009. A different kinetic profile of ochratoxin A in mature male rats. Food Chem Toxicol 47, 1921-1927.

Wangikar, P.B., Dwivedi, P., Sinha, N., Sharma, A.K. and Telang, A.G., 2005. Teratogenic effects in rabbits of simultaneous exposure to ochratoxin A and aflatoxin B1 with special reference to microscopic effects. Toxicology 215, 37-47.

Wangikar, P.B., Dwivedi, P. and Sinha, N., 2004. Effect in rats of simultaneous prenatal exposure to ochratoxin A and aflatoxin B1. I. Maternal toxicity and fetal malformations. Birth defects research.Part B, Dev Rep Toxicol 71, 343-351.

WHO (World Health Organisation), 2008. Safety evaluation of certain food additives and contaminants. WHO Food Additives Series, No. 59.

Wong, Z.A. and Hsieh, D.P.H., 1980. The comparative metabolism and toxicokinetics of aflatoxin B1 in the monkey, rat, and mouse. Toxicol Appl Pharmacol 55, 115-125.

Zepnik, H., Völkel, W. and Dekant, W., 2003. Toxicokinetics of the mycotoxin ochratoxin A in F 344 rats after oral administration. Toxicol Appl Pharmacol 192, 3644. 


\section{Legend to figures:}

Figure 1: Microscopic images of liver samples. A progressive lesional state can be observed. A) Normal liver of a control sample. B) Focal cell necrosis and discreet degeneration of cytoplasm after $24 \mathrm{~h}$. C) Intense tumefaction of hepatocytes, cell proliferation and initial fibrosis in porta spaces after 48 h. D) Necrosis and inflammatory response maintained fibrosis around bile canaliculi in porta spaces after $72 \mathrm{~h}$. E) Moderate tumefaction of cytoplasms, proliferation of bile canaliculi and portal fibrosis after $96 \mathrm{~h}$, and also F) binucleated hepatocytes in regenerative phenomena. Magnification of Ex100. Magnification of A, C and D x200. Magnification of B and F $\mathrm{x} 400$.

Figure 2: Plasmatic (A) or tissue (B) concentrations of OTA overtime after a single oral administration of AFB1+OTA $(0.25 \mathrm{mg} / \mathrm{kg}$ bw of AFB1 and $0.5 \mathrm{mg} / \mathrm{kg}$ of OTA in $\left.\mathrm{NaHCO}_{3} \cdot \mathrm{H}_{2} \mathrm{O}(0.1 \mathrm{M} \mathrm{pH} 7.4)\right)$. The plasma Cmax and Tmax and tissue values obtained at $24 \mathrm{~h}$ in this study and in Vettorazzi et al. $(2010,2011)$ under similar experimental conditions have been included.

Figure 3: Superimposed chromatograms of plasma samples collected 10 and 30 minutes, 4,8 and $24 \mathrm{~h}$ after administration. Chromatographic conditions were modulated in order to show the AFB1 metabolites that appeared in plasma samples. Chromatograms of a control plasma sample and a spiked plasma sample with AFB1 and OTA have been superimposed in the plot. 